\title{
More than One Flaw: Reply to Millican
}

Millican (2004) claims to have detected ‘the one fatal flaw in Anselm’s ontological argument'. In his view, when we read Anselm's argument correctly, we find that it fails only because of a logically shallow but subtle scope ambiguity in 'Anselm's key phrase', viz. 'something than which no greater can be thought'. Moreover, according to Millican, this ‘straightforward and compelling’ objection to Anselm's argument 'generalises easily to other versions of the Ontological Argument'; i.e., according to Millican, all ontological arguments fail because of subtle scope ambiguities in the key phrases that they employ.

I think that there is more than one important flaw in Millican (2004). First, Millican's reconstruction of Anselm's argument actually does violence to the original text. Second, Millican's generalised objection fails to diagnose any flaw in a vast range of ontological arguments. Third, there are independent reasons for thinking that Millican's generalized objection is unpersuasive. And fourth, despite the dismissive remarks that Millican makes about Oppy (1995), it seems to me that many of the good features of Millican's analysis are to be found in Oppy (1995)(1996)(1997)(2001).

\section{Millican's Reconstruction of Anselm's Argument}

Millican works with the Charlesworth (1965) translation of the Proslogion. In particular, with one footnoted exception, he takes the following to be the text in 
which Anselm's ontological argument is set out (Millican's preferred reading of the one sentence is given in square brackets.):

... But surely, when this same Fool hears what I am speaking about, namely 'something-then-which-nothing greater-can-be-thought', he understands what he hears, and what he hears is in his mind, even if he does not understand that it actually exists. For it is one thing for an object to exist in the mind, and another thing to understand that an object actually exists. Thus, when a painter plans beforehand what he is going to execute, he has [the picture] in his mind, but he does not yet think that it actually exists because he has not yet executed it. However, when he has actually painted it, then he both has it in his mind and understands that it exists because he has now made it. Even the Fool, then, is forced to agree that something-than-whichnothing-greater-can-be-thought exists in the mind, since he understands this when he hears it, and whatever is understood is in the mind. And surely thatthan-which-a-greater-cannot-be-thought cannot exist in the mind alone. For if it exists solely in the mind even, it can be thought to exist in reality also, which is greater. [For if it exists solely in the mind, something that is greater can be thought to exist in reality also.] If then that-than-which-a-greatercannot-be-thought exists in the mind alone, this same that-than-which a greater-cannot-be-thought is that-than-which-a-greater-can-be-thought. But this is obviously impossible. Therefore there is absolutely no doubt that something than-which-a-greater-cannot-be-thought exists both in the mind and in reality. 
Millican claims that the argument in this paragraph is more perspicuously set out as follows:

1. The phrase 'a-nature-than-which-no-greater-nature-can-be-thought' is clearly understood by the Fool, and apparently makes sense.

2. Hence we can take the phrase 'a-nature-than-which-no-greater-naturecan-be-thought’ as successfully denoting some specific nature.

3. A nature that is instantiated in reality is greater than one that is not.

4. So if a-nature-than-which-no-greater-nature-can-be-thought were not instantiated in reality, then it would be possible to think of a nature that is greater (for example, any nature that is in fact instantiated in reality)

5. But this would be a contradiction, since it is obviously impossible to think of a nature that is greater than a-nature-than-which-no-greaternature-can-be-thought.

6. Therefore a-nature-than-which-no-greater-nature-can-be-thought must indeed be instantiated in reality.

In this presentation, Millican claims to be reconstructing Anselm's argument in a 'more sympathetic theoretical context that it is usually permitted' (457); but nonetheless, he insists that there is a 'step-by-step correspondence' with the more familiar, literal, mentalistic reconstruction, and 'the logic by which the conclusion is reached is structurally parallel' (458): 
1. The Fool understands the phrase 'something-than-which-nothing-greatercan-be-thought'.

2. Hence something-than-which-nothing-greater-can-be-thought exists at least in the Fool's mind.

3. It is greater to exist in reality than to exist in the mind alone.

4. So, if that- than-which-nothing-greater-can-be-thought existed only in the Fool's mind, then it would be possible to think of something greater (that is, something existing in reality also)

5. But this would be a contradiction, since it is obviously impossible to think of something greater than than-which-nothing-greater-can-bethought.

6. Therefore something- than-which-nothing-greater-can-be-thought must exist both in the Fool's mind and in reality also.

I think that it is not even remotely plausible to suppose that Millican's 'reconstruction' fits the argument that we are given in Proslogion 2. In Anselm's text, the last sentence-as well as some of the earlier sentences—make it clear that he is committed to a theoretical framework in which there is just one 'something' that exists both in the understanding and in reality, not a theoretical framework in which there are natures in the understanding that are (at least in some cases) instantiated by things in reality. The standard mentalistic version of the argument and Millican's reconstruction in terms of natures do not share the same logical form; but all of the textual evidence speaks in favour of the standard mentalistic version. 
Suppose Anselm did intend for his ‘key expression’ to be read as ‘a-nature-thanwhich-no-greater-nature-can-be-thought'. Then it would simply make no sense for him to conclude his argument by saying that there is absolutely no doubt that anature-than which-a-greater-cannot be thought exists both in the mind and in reality (for, a fortiori, natures that exist in the mind all exist in reality); and nor would it make any sense for him to conclude his argument by saying that there is absolutely no doubt that a-nature-than which-a-greater-cannot be thought is instantiated both in the mind and in reality (since it is evident that the nature is not instantiated in the Fool's mind); and nor would it make any sense for him to conclude his argument by saying that there is absolutely no doubt that a-beingthan which-a-greater-cannot be thought exists both in the mind and in reality (since the whole point of introducing the theory of natures is to avoid commitment to the claim that there are beings that exist in the mind). But there are no other alternative interpretations that seem even remotely plausible.

(Perhaps it is also worth registering that Millican's preferred rendering of the highlighted sentence is odd. In the original formulation, the 'also' is apt: 'if it exists solely in the mind, it can be thought to exist in reality also'. But, in the Anscombe reformulation that Millican prefers, the ‘also' seems inappropriate: ‘if it exists solely in the mind, something that is greater can be thought to exist in reality also'. Why 'also'? After all, 'it' is supposed not to exist in reality; and there is no reason to suppose that the 'something' exists in the mind.) 
Of course, even if Millican’s reconstruction won't pass muster as an interpretation of the text of the Proslogion, it does not follow that the remainder of his discussion is without interest. After all, the text of the Proslogion has proven a very fertile source for the construction of very different formalized arguments, and the analysis of those arguments is—at least in my opinion—a fascinating business. The argument that Millican analyses is worthy of attention, as is his further claim that finding the flaw in this argument provides a key to the detection of flaws in all other ontological arguments.

\section{Millican's Analysis of the "Natures" Argument.}

Millican claims that the key phrase 'a-nature-than-which-no-greater-nature-canbe-thought' can be read in several different ways. It might mean:

1. A nature that is so great that no nature is greater; or

2. A nature that is so great that no nature can be thought greater; or

3. A nature that can be thought so great that no nature is greater; or

4. A nature that can be thought so great that no nature can be thought greater.

On the first reading, the argument is sound, but the conclusion of the argument is only the trivial claim that the greatest instantiated nature is instantiated. On the second reading, the inference from 1 . to 2 . is question begging, since there will only be a nature of this kind if God exists. On the third and fourth readings, the 
reductio at step 5. fails, because there is no contradiction in the supposition that such a nature is exceeded in actual greatness.

In short, then, Millican claims that the argument admits of different readings, on some of which the argument is invalid, on some of which it is plainly questionbegging, and on some of which the argument is sound, but establishes a conclusion that has absolutely no religious significance.

This analysis conforms nicely to my previous work on ontological arguments. In Oppy (1995), I argued that, when the most promising formulations of ontological arguments are examined, they turn out to admit of different readings, on some of which the argument is invalid, and on others of which the arguments are plainly question begging. Then, in Oppy (1997), I noted that there are some interesting formulations of ontological arguments_-including arguments that might be suggested by Proslogion 2 — that admit of different readings, on some of which the argument is invalid, on some of which it is plainly question-begging, and on some of which the argument is sound, but establishes a conclusion that has absolutely no religious significance.

Moreover, the virtues that Millican claims for this kind of analysis are all virtues to which I have drawn attention in pressing the merits of this kind of approach to ontological arguments. While ontological arguments often involve investment in controversial metaphysical assumptions, I hold that there are no cases in which one needs to buy into controversial metaphysical disputes in order to show that 
those arguments are unsuccessful. (See, in particular, the introductory section in Oppy (1996).) Even if there are other compelling reasons for rejecting the 'natures' argument that Millican sets out, it seems to me that Millican is right to think that there are quite shallow considerations that suffice to overthrow the argument.

\section{Millican's Generalisation}

Millican claims that his criticism of the 'natures' argument generalises:

Such arguments typically proceed by referring to or specifying some 'entity' (nature, type, concept, or whatever) whose 'reality' (instantiation, actuality, existence, or whatever) is to be proved. The means of reference or specification will involve some suitably godlike description whose content is then supposed to provide a means of demonstrating the reality of the entity in question. For simplicity, suppose that the description used is 'the G', in which case the argument will proceed by using this description to identify the entity in question and then unpacking the descriptive content with the aim of showing that the $G$ must really exist. To counter such an argument, I recommend that the atheist should face its proponent with a simple dilemma through the following question: 'Is it necessary, in order to satisfy the description 'the G', that an entity really possess the properties that qualify it as the denotation of that description, or is it sufficient that it be thought of as possessing the relevant properties? If it is necessary that the $G$ really have 
those properties, then the atheist can reasonably question whether 'the G' succeeds in denoting any godlike entity in the first place; if it is not necessary that the $G$ really have those properties, then the theist cannot hope to prove that any entity thus denoted must therefore really exist with those properties. (468)

A natural first objection to make to this proposal is that very many ontological arguments do not involve specifications of natures, or types, or concepts, or properties, but rather they involve specifications of objects. True enough, some ontological arguments are given higher-order formulations (involving reference to and/or quantification over natures, types, properties, concepts; and the like); but the vast majority of ontological arguments are given first-order formulations in terms of objects. Of course, it is often the case that standard formulations of ontological arguments involve sentential operators_- 'it is possible that', 'it can be thought that', and the like - that have readings on which there is cancellation of the ontological commitments that would be incurred by 'naked' uses of the relevant terms: but it would be a serious mistake to suppose that the use of these operators in those formulations of ontological arguments brings it about that those formulations are higher-order. If I say 'It is conceivable that God exists', it may be that there is a suitable higher-order paraphrase for what I have said- 'It is conceivable that such-and-such a nature is instantiated', say; but it remains the case that the utterance that I have made is plainly first-order. 
Perhaps it might be said that it is not entirely clear that Millican doesn't mean for his critique to apply to first-order ontological arguments. (After all, on standard views, it is not the existence of natures, types, properties, concepts, and the like that is problematic, but rather their instantiation. So perhaps Millican intends his 'exists' to pick up 'objects' under 'and the like' in his characterization of the standard form of ontological arguments. The waters are muddied here by the possibility of natures, types, properties, concepts and so forth whose existence depends upon their instantiation: some theories maintain that there cannot be uninstantiated natures, types, properties, concepts, and the like. I suspect that it is more likely that Millican includes 'exists' in his characterization of ontological arguments to allow for these kinds of views.) But, if Millican does mean for his analysis to apply to first-order ontological arguments, then it is clearly appropriate to try it out on them.

Consider the following argument (discussed in Oppy (1995:59ff.)):

1. I conceive of a being than which no greater can be conceived.

2. If a being than which no greater can be conceived does not exist, then I can conceive of a being greater than a being than which no greater can be conceived-namely, a being than which no greater can be conceived which exists.

3. I cannot conceive of a being greater than a being than which no greater can be conceived.

4. (Hence) A being than which no greater can be conceived exists. 
The key expression here is 'being than which no greater can be conceived'. In answer to Millican's question, a being can only satisfy this expression if it really possesses the properties that qualify it as the denotation of that description. But, of course, there are readings of the first premise of this argument on which it is true even if there is no being that satisfies the description in question. (I can conceive of Santa Claus even though there is no Santa Claus.) So, Millican's dilemma is no help at all in diagnosing what is wrong with the argument. Moreover, when we look closely, we see that this argument simply doesn't conform to the specification 'proceed by using the given description to identify the entity in question and then unpack the descriptive content with the aim of showing that the $G$ must really exist’.

I take it that this kind of example makes it clear that no general critique of ontological arguments can depend simply on considerations about descriptive terms: account must also be taken of sentential operators, and their interactions with descriptive terms. As it happens, there is a general critique of ontological arguments in Oppy (1995) that does aim to take account of sentential operators and their interactions with descriptive terms. This critique is formulated for firstorder ontological arguments, with the rider that higher-order ontological arguments can all receive adequate first-order paraphrase.

In any version of one of the historical arguments, it will be the case that the singular terms and quantifiers—names, definite descriptions, indefinite 
descriptions, and so forth—used in the statement of the argument—-to refer to, or to denote, or to range over a collection that is supposed to include, that divine object whose existence is to be established by the argument-either occur embedded in the scope of further sentential operators or do not occur thus embedded. If they do not occur thus embedded, than an opponent of the argument can reasonably object that the question has been begged. On the other hand, if they do thus occur, then there is a question about the detachment of the conclusion of the argument from the scope of the operators. If the operators are extensional—and hence permit the inference of the desired conclusion - then, as in the case of the modal arguments, an opponent of the argument can again reasonably insist that the question has been begged. But, if the operators are intensional, then they won't permit the inference of the desired conclusion. So, no matter how the argument is formulated, an opponent can always either (i) reasonably claim that the question has been begged or else (ii) object that the inference is simply invalid. (115)

Of course, as I go on to point out, this critique requires qualification to take account of the views of free logicians and Meinongians who allow that it is possible to make 'naked' use of the referential apparatus of a language—singular terms, quantifiers, and so forth—without incurring actual ontic commitments. But on all views of this kind, there has to be some kind of restriction or distinction imposed to make it possible to explain the key difference in ontic status between (at least speaking loosely) existent and non-existent entities. Perhaps we allow that predication is ambiguous; perhaps we allow that there are two different kinds 
of properties (say, characterising and non-characterising); or perhaps we take some other tack. But, however we proceed, we render ourselves vulnerable to the general objection, since we have one kind of predication (or class of properties) that is ontologically unproblematic, and a second kind that is not. Naked uses of the latter are question begging; naked uses of the former don't entail naked uses of the latter; and protected uses of either the former or the latter don't entail naked uses of the latter.

Since Millican’s 'natures' argument is a higher-order argument, the application of this general objection to that argument depends upon finding a first-order paraphrase of the argument. I think that any such paraphrase is bound to recast the argument as a Meinongian argument. (For those familiar with the relative consistency proof for Meinongian semantics in Parsons (1980), this should come as no surprise. Millican’s favoured representation of natures—< property $_{1}$, property $_{2}, \ldots>$ - does duty for Parsons as a representation of Meinongian objects.) Reinterpreting natures as Meinongian objects, and making other appropriate changes in terminology, we get the following argument:

1. The phrase 'an-object-than-which-no-greater-object-can-be-thought' is clearly understood by the Fool, and apparently makes sense.

2. Hence we can take the phrase 'an-object-than-which-no-greater-objectcan-be-thought’ as successfully denoting some specific object.

3. An object that exist in reality is greater than one that is not. 
4. So if an object-than-which-no-greater-object-can-be-thought did not exist in reality, then it would be possible to think of an object that is greater (for example, any object that in fact exists in reality)

5. But this would be a contradiction, since it is obviously impossible to think of an object that is greater than an-object-than-which-no-greaterobject-can-be-thought.

6. Therefore an-object-than-which-no-greater-object-can-be-thought must indeed exist in reality.

What we say in response to this argument depends upon the further assumptions that we make about the theory of objects.

If we opt for an ambiguity of predication view then, for example, we might allow that an object than which no greater object can be thought will certainly encode actual existence, but whether it exemplifies actual existence depends upon whether or not it actually exists. Read one way, premise 3 is false; read the other way, while premise 3 is true, there is no contradiction at line 5 (and so the argument is invalid).

If we opt for a two kinds of properties view, then we need to decide whether or not to treat 'greatness' as a characterizing property, where the answer to this question depends upon whether or not 'greatness' is 'existence-entailing'. On the one hand, if 'greatness' is non-characterising, then the inference at line 2 is 
invalid. On the other hand, if 'greatness' is characterising, then (as in the previous case), there is no contradiction at line 5 (and so the argument is invalid).

While there are more details on which one might linger, I think that it is already highly plausible to suggest that there is a sense in which the general objection from Oppy (1995) does adequately handle Millican’s argument: we can find an analysis on which the claim of the general objection is borne out in the case of the ‘natures’ argument. Moreover, since the range of cases that can be handled by Millican's proposal is plausibly properly contained in the range of cases that can be handled by that general objection, it also seems reasonable to suggest that, at best, Millican offers a special case of the more general treatment of ontological arguments suggested in Oppy (1995) (1996) (1997) (2001).

\section{Millican's Critique of Oppy (1995)}

Millican sees the relationship between his generalization of the objection to the 'natures’ argument and the general objection of Oppy (1995) rather differently. On his account, Oppy (1995) proposes a ‘separate realms principle’, and applies this principle to a wide range of ontological arguments. According to Millican, a 'separate realms principle' proposes that 'a gulf exists between the realm of concepts and the realm of real things: no matter what concepts we devise, it is always a further question whether or not they are realised or instantiated in reality’ (444). Moreover, according to Millican: 
As applied to Anselm's argument, the Separate Realms Principle takes issue with the steps from (1) to (4) by facing him with a dilemma over the realm within which they are to be interpreted. If, on the one hand, (2) and (4) are to be interpreted as propositions within the realm of concepts- that is, concerning only the content of the Fool's conception-then (2) can indeed be inferred from (1) but step (4) fails because external existence is irrelevant to that realm. ... If, on the other hand, (2) is to be interpreted in such a way that one can only 'think' about something that exists in reality, then the atheist can simply refuse to accept is as a legitimate implication from (1). (444)

And:

In addressing the Proslogion II argument itself, Oppy focuses on three very simplified 'interpretations' of that argument, two of which are so distant from Anselm's words as to be virtually unrecognizable, while the otherdubbed the conceptual interpretation—-plays into the hands of this 'general objection' both by the simple way in which it is represented and also by being phrased entirely in terms of conceiving and conceivability.

There are several points that might be raised in connection with these claims.

First, as I have had occasion to note elsewhere, it is not true that the analyses that I give of the different classes of ontological arguments that I identify are 'applications of a separate realms principle that proposes a gulf between the realm 
of concepts and the realm of real things'. This can be seen, for example, in my analyses of definitional arguments, modal arguments, Meinongian arguments, experiential arguments and Hegelian arguments; and also in the case of my analysis of conceptual arguments, though it is true in this last case that I do provide some discussion of what someone who insists on a separation of realms is denying (namely 'that there are a priori considerations that will lead anyone who is antecedently and reasonably agnostic about the existence of nonmental entities of a certain kind to the conclusion that there really are entities of that sort'). Even in the case of conceptual arguments, the bulk of the analysis concerns different readings of the expression 'conceive of $\mathrm{X}$ ' (some of which are ontologically committing and some of which are not). Rather than proposing a gulf between the realm of concepts and the realm of real things, my analysis asks about the readings of expressions of the form 'conceive of $\mathrm{X}$ ' that those who do not already suppose that X exists should be prepared to accept.

Second, as I have also had occasion to note elsewhere-and as the text itself makes clear — the analyses of the various classes of ontological arguments in Oppy (1995) do not in any way depend upon the general objection. The general objection is meant to be an argument against the possibility of a successful ontological argument; it is not meant to be a recipe for successfully identifying the flaws in particular ontological arguments. True enough, it seemed to me that the general objection is supported by the particular analyses given of the various identified classes of ontological arguments: but, as I insisted at various points in Oppy (1995), those analyses are very different in nature. 
Third, there is nothing in Oppy (1995) to support the suggestion that I was there committed to 'the analysis of Anselm's argument' that Millican claims would be given by one who endorses a ‘separate realms principle’. True enough, I do allow that there are 'interpretations' of the Proslogion II-i.e. arguments that are at least loosely suggested by that text—-that are vulnerable to this kind of analysis, but I make it clear that I think that there are many different 'interpretations' of that text that admit of many different kinds of analysis. Moreover, while it is true that I only give detailed analyses for some relatively simple arguments (at least in the chapter on the historical arguments), I make it clear that I think that similarthough more complex-considerations will suffice for more complicated ontological arguments, and I have explained above how Millican’s 'natures’ argument could be handled in the framework of Oppy (1995). (For some of my views on the argument that I take Anselm to have actually given, one might consult Oppy (1996) or Oppy (2006).)

\section{One Last Flaw}

It would be remiss of me to conclude this piece without drawing attention to the fact that I have long given up on the general objection of Oppy (1995)—see Oppy (2001) (2006) for the details. While I think that it is London to a brick that there is no successful ontological argument, I do not think that the general objection of Oppy (1995) provides a conclusive reason to suppose that there cannot be a successful ontological argument. The problem is that, while all ontological 
arguments with which I am familiar that are not crippled by more obvious flawse.g. the possession of a premise that all can acknowledge is uncontroversially false (see, for example, Maydole (2004), discussed in Oppy (2004))—do fit the structure of the general objection, there is no really good argument that there couldn't be a successful ontological argument that I haven't yet encountered that evades the general objection.

Millican claims that one of the virtues of his analysis is its modesty: it requires no metaphysical heavy lifting. But there is another sense in which his analysis and the general objection of Oppy (1995) are quite immodest: they undertake to prove to all rational beings that there cannot be a successful ontological argument. Plainly enough, this result is more than the opponent of ontological arguments requires. In particular, a non-believing opponent of ontological arguments should be satisfied with the claim that they have no reason to believe that there is a persuasive ontological argument. This condition will be satisfied if, for example, the non-believer has good reason not to be persuaded by any extant ontological arguments and good (independent) reason for thinking that there are no supernatural entities.

That there is a class of ontological arguments that fail because of subtle scope ambiguities in key terms — or that there is a wider class of ontological arguments that fail because there is a subtle ambiguity in the interpretation of at least one of the premises of those arguments—is an interesting point that helps to explain why those ontological have seemed attractive to some, but also why those ontological 
arguments fail. However, I don’t see why non-believers should suppose that there is a need to extend this observation into a knockdown demonstration that there simply cannot be a successful ontological argument. Of course, non-believers will suppose that every possible disambiguated ontological argument is either invalid, or unsound, or question-begging, or possessed of a conclusion that has no religious significance. But the proper justification for this belief goes by way of the independent reasons that non-believers have for supposing that there are no gods or other supernatural entities.

\section{References}

Maydole, R. (2004) “The Modal Perfection Argument” Philo 6, 2, 299-313

Millican, P. (2004) “The One Fatal Flaw in Anselm’s Argument” Mind 113, 451, 437-476

Oppy, G. (1995) Ontological Arguments and Belief in God New York:

Cambridge University Press

Oppy, G. (1996) “Ontological Arguments” Stanford Electronic Encyclopedia of Philosophy http://plato.stanford.edu/entries/ontological-arguments/ (revised 2002)

Oppy, G. (1997) “Pantheism, Quantification, and Mereology” Monist, 80, 2, 32036

Oppy, G. (2001) “Reply to Langtry” Sophia 40, 73-80

Oppy, G. (2004) “Maydole’s 2QS5 Argument” Philo 7, 2, 203-11

Oppy, G. (2006) Arguing about Gods Cambridge: Cambridge University Press 
Parsons, T. (1980) Non-Existent Objects New Haven: Yale University Press 